\title{
Lead extraction: The road to successful cardiac resynchronization therapy
}

\author{
Aleksander Maciąg ${ }^{1}$, Paweł Syska $^{1}$, Maciej Sterliński ${ }^{1}$, Andrzej Przybylski \\ Ewa Sitkowska ${ }^{3}$, Artur Oręziak², Maria Bilińska², Mariusz Kuśmierczyk ${ }^{4}$, Hanna Szwed $^{1}$ \\ ${ }^{1} 2^{\text {nd }}$ Coronary Disease Department, Institute of Cardiology, Warsaw, Poland \\ ${ }^{2}$ Arrhythmia Department, Institute of Cardiology, Warsaw, Poland \\ ${ }^{3}$ Anesthesiology Department, Institute of Cardiology, Warsaw, Poland \\ ${ }^{4}$ Cardiosurgery and Transplantology Department, Institute of Cardiology, Warsaw, Poland
}

\begin{abstract}
Background: Still increasing life expectancy in patients with implanted devices and large number of leads more and more often induce the need to cure the treatment complications or to change especially to cardiac resynchronization therapy (CRT). In order to prevent further complications, the possibility of damaged or redundant leads extraction should be taken into consideration. The aim of the paper was to assess the effectiveness and safety of transvenous lead extraction (TLE) with co-implantation of resynchronization systems.

Methods and results: Between 2008 and March 2013, the system removal with TLE was conducted in 246 patients. In 38 patients (11 women, 28.9\%), aged 43-79 (mean 65 years), it was combined with co-implantation of CRT-pacemaker or defibrillator (CRT-P/D). Indications for TLE covered: lead failure in 21 (55.3\%) patients, redundant leads in 6 (15.8\%), and the occluded venous system in 7 (18.4\%). The up-grade of the pacemaker or defibrillator system to $C R T-D$ was performed in 19 cases, CRT-P/D revision in next 19. Together 32 defibrillation leads and 42 pacing leads (27 left ventricular leads, and 1 epicardial lead) were implanted. The intended clinical target - an effective resynchronization therapy — was obtained in all patients. There was no case of death or severe complications. In 2 cases of venous occlusion, the implantation on the contralateral side was required.

Conclusions: TLE enables effective resynchronization therapy also in the case of the presence of too many leads, occlusion of the venous system or lead failure. Significant technical problems can occur especially in patients with venous system occlusion. (Cardiol J 2015; 22, 2: 188-193)
\end{abstract}

Key words: lead extraction, cardiac resynchronization therapy, central venous occlusion, lead failure

\section{Introduction}

Increasing life expectancy in patients with cardiac implantable electronic devices and large number of leads in the venous system more and more frequently generate the need to cure the treatment complications or to change the therapy.
It results from the primary disease progression as well as from expanding indications for more advanced form of therapy, e.g. automatic implantable cardioverter-defibrillator (ICD) or resynchronization therapy (CRT) [1, 2]. In order to prevent further complications, the possibility of damaged or redundant lead extraction should be taken into

Address for correspondence: Aleksander Maciąg, $\mathrm{MD}, \mathrm{PhD}, 2^{\text {nd }}$ Coronary Disease Department, Institute of Cardiology, ul. Spartańska 1, 02-637 Warszawa, Poland, tel: +48 2234340 50, fax: +48 2284495 10, e-mail: maciag_o@poczta.onet.pl 
consideration in the case of longer life expectancy. Although in some patients adding the next lead can be taken into account, such proceeding could only postpone the problem and, in further perspective, mean the impairment of the system function. Additionally, in case of the venous system occlusion, either on the level of subclavian vein, innominate vein or superior vena cava, which prevents a simple change of stimulation mode, the retrieval of the venous access is a reasonable alternative. Meeting these expectations constitutes a challenge for the operators performing transvenous lead extraction (TLE), since except for the lead extraction, which sometimes turns out very laborious itself, usually the equally demanding co-implantation of the resynchronization system should be conducted.

The aim of the paper was to assess the effectiveness and safety of TLE with co-implantation of resynchronization systems.

\section{Methods}

Between 2008 and March 2013, the system removal with TLE was conducted in 246 patients in the clinic. In $93(37.8 \%)$ patients, indications for the intervention were infectious complications such as pocket infection or infective endocarditis. The remaining 153 patients had non-infectious indications. Four hundred and seven leads were extracted in total. Data concerning patients, who had the lead extraction procedure combined with co-implantation of CRT-pacemaker or defibrillator (CRT-P/D) resynchronization system, were selected from the TLE procedures database for the need of the analysis. Table 1 shows patient proportion in particular years of keeping the registry. It is clearly visible that proportion of non-infected patients is gradually growing. Also, increasing CRT population size corresponds with total patients group and operator's experience. The selected CRT group equaled 38 (11 women, $28.9 \%$ ), aged between 43 and 79 (mean age 65) years. In the examined group, 23 patients had resynchronization system previously implanted (pacemaker in 5 cases, in the remaining 18 cases - cardioverter-defibrillator with resynchronization function), 9 patients had single or dual chamber pacing system and the rest of patients - single or dual chamber cardioverter-defibrillator. Table 2 presents clinical characteristics of the group.

All lead extraction procedures with co-implantation of a new system were performed in the case of non-infectious indications. In 21 (55.3\%) patients they were conducted due to lead damage, in $6(15.8 \%)$ - due to the necessity of the extraction

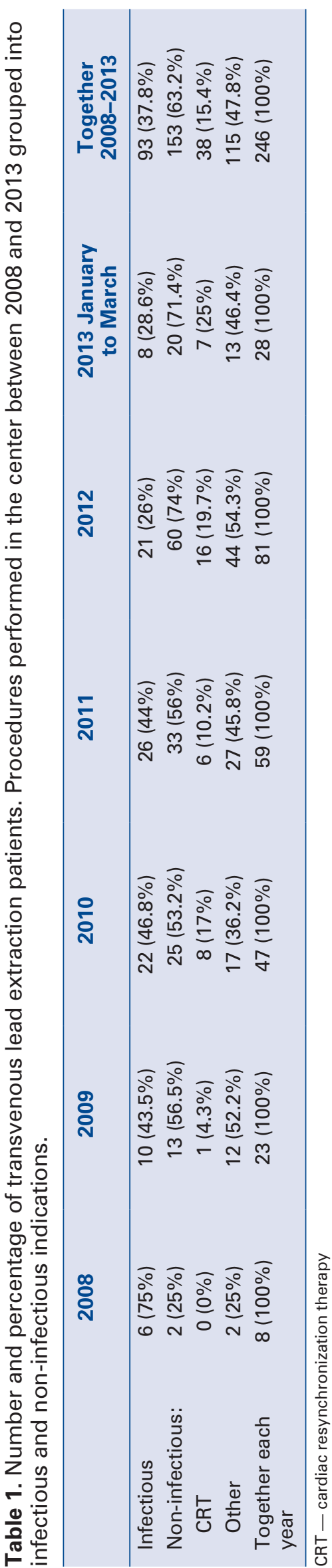


Table 2. Clinical characteristics $(n=38)$.

$\begin{array}{lc}\text { Age [years] } & 65.4(43-79) \\ \text { Female } & 11(29 \%) \\ \text { NYHA class: } & 11(29 \%) \\ \text { II } & 26(68.5 \%) \\ \text { III } & 1(1.5 \%) \\ \text { IV } & 19(50 \%) \\ \text { Primary disease/indication for implantation: } \\ \text { Post infarction HF } & 13(34.2 \%) \\ \text { Dilated cardiomyopathy } & 4(10.5 \%) \\ \text { Congestive HF caused by VHD } & 2(5.3 \%) \\ \text { Systolic dysfunction in HCM } & \\ \text { Indication for pacing: } & 13(34.2 \%) \\ \text { AV heart block - II }{ }^{\circ} \text { or III } & 2(5.3 \%) \\ \text { Sick sinus syndrome } & \\ \text { Type of previously implanted device: } & 18(47.4 \%) \\ \text { ICD with CRT } & 9(23.7 \%) \\ \text { Dual/single chamber pacemaker } & 6(15.7 \%) \\ \text { Dual/single chamber ICD } & 5(13.2 \%) \\ \text { Pacemaker with CRT } & \end{array}$

NYHA - New York Heart Association; HF — heart failure; VHD valvular heart disease; HCM - hypertrophic cardiomyopathy; AV - atrioventricular; ICD - implantable cardioverter-defibrillator; CRT - cardiac resynchronization therapy

of leads that were not failed but redundant after the change of pacing mode, in $7(18.4 \%)$ patients - due to the occlusion in venous system and necessity to restore the vascular access (in 2 cases - superior vena cava, in the remaining cases - subclavian and innominate vein), and due to the lead dislocation in further $4(10.5 \%)$ cases. All patients had indications for the implantation of resynchronization system or for continuation of such therapy. The patient referred for the procedure in New York Heart Association (NYHA) class IV had cardiac competence deterioration due to left ventricular lead dislocation and the loss of resynchronization stimulation.

Considering the complexity of the procedure and potential complications, the interventions were conducted in operating room or hybrid operating room conditions in order to provide cardiosurgical backup and safe general anesthesia process. Operations were performed under fluoroscopy. Patients with unsatisfactory escape rhythm were protected with temporary pacing lead from the femoral approach (6 patients, $15.8 \%$ of the study group).

Since the procedure objective was to perform the new lead implantation, the venous approach was provided through the catheter inserted to axillary or subclavian vein and the guide wire was advanced to the right atrium. If it was not possible

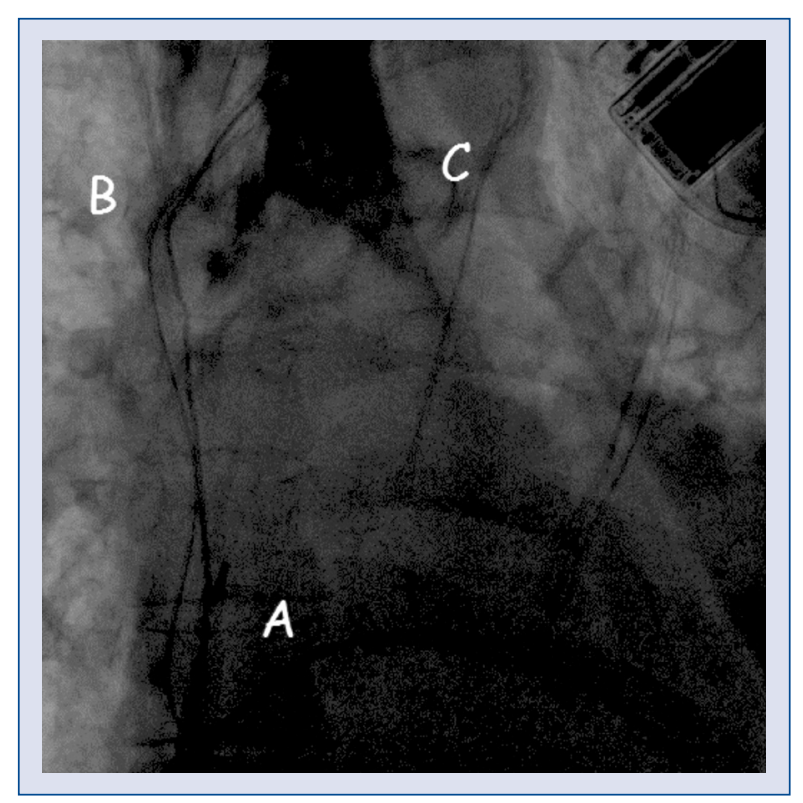

Figure 1. Venous approach retrieval in patient with subclavian vein occlusion. Vascular loop countertraction from femoral approach was used to tighten the atrial lead and to advance the vascular sheaths through the occlusion. The end of vascular loop $(A)$, end of telescopic sheath (B) as well as contrast extravasation after innominate vein dissection (C) are visible.

due to venous occlusion or in the case of multiple lead implantation, the venous access was restored after lead extraction. If it was impossible to regain the access, the resynchronization system was implanted on the contralateral side.

In 1 case described previously it was indispensable to use more advanced techniques to regain the venous system access [3]. In one of the patients, the adhesions between the lead and the vascular system were too weak to overcome the occlusion in the innominate vein with telescoping sheaths because the moderate traction caused complete removal of the lead before the sheath reached the other side of the occlusion. In order to breach the occluded section of the vessel it was necessary to use the traction from femoral access, through the loop that was hooked on the next endocardial lead. Only such a method enabled to advance the telescopic sheaths to the right atrium (Fig. 1).

The lead extraction was conducted according to the method described above. The applied techniques were changed gradually from less aggressive to more complex ones, that is from the simple traction, through traction combined with the use of mechanical sheaths, to the use of rotating threaded tip sheaths $[4,5]$.

Most commonly used was the device traction — with mechanical telescopic sheaths — steel, 
polypropylene or Teflon (Cook Vascular, Leechburg, PA, USA) twisted manually along the lead to cut the adhesions in the vascular system. The lead stiffness, with the lumen maintained, was obtained by means of a standard stylet or a locking stylet Liberator Beacon (Cook Vascular, Leechburg, PA, USA) if necessary [6].

After the lead extraction, the remaining ones were assessed macroscopically in the available section and under fluoroscopy in the intravascular segment. Additionally, electrical parameters were controlled so that the leads could be used in the new system. They were extracted if they did not secure the safe system function.

\section{Results}

Sixty-three leads were extracted: 62 (98.4\%) were extracted completely, in $1(1.6 \%)$ case the clinical target was fully obtained, but the radiological one was only partial - with a part smaller than $2 \mathrm{~cm}$ left inside. From 1 to 4 electrodes were extracted (mean 1.67 electrode per patient). The mean time from implantation to lead extraction equaled 56 months (from 6 to 194 months).

In total, 42 pacing leads (66.7\%) and $21(33.3 \%)$ defibrillating leads were extracted; out of those: $34(54 \%)$ leads had active fixation and $29(46 \%)-$ passive fixation. Simple traction was effective in the case of $26(41.3 \%)$ leads, device traction - in further 37 cases. From the number of 11 left ventricular leads, implanted at an average $36.6(58.3 \%)$ months earlier (14-69 months), 5 (45.5\%) were extracted by means of simple traction and $6(54.5 \%)$ by means of device traction. All of them were extracted undamaged. In patients with successful simple traction, the mean time from implantation to lead extraction was 24 months (from 6 to 108 months), whereas in case of device traction 78 months (from 14 to 194 months).

Venous approach retrieval was not successful in 2 out of 7 cases (28.6\%) and resynchronization system implantation on the contralateral side was implanted.

The up-grade of single/dual chamber or biventricular pacemaker, and cardioverter-defibrillator to CRT-D system was performed in 19 patients. In other patients, the revision of resynchronization systems was conducted - CRT-P in 1 case, in the remaining 18 - CRT-D, due to the damage of the leads or their dislocation. Figure 2 displays the types of implanted systems before lead extraction procedures and after new implantation.

New leads were implanted to coronary sinus system as well as to the right heart through previ-

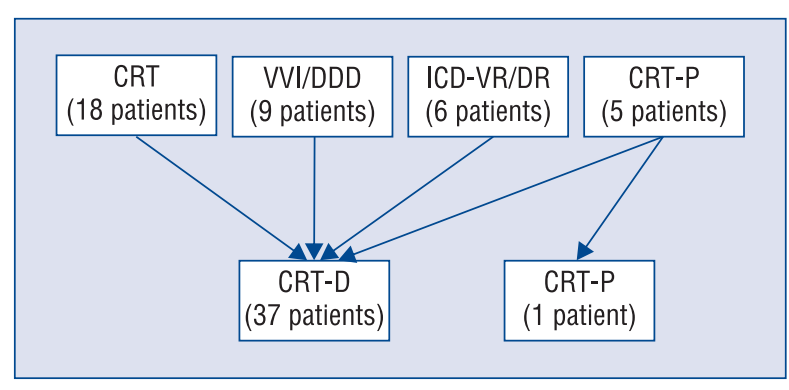

Figure 2. Types of implanted systems before lead extraction as well as after the new implantation; CRT-D - implantable cardioverter-defibrillator with cardiac resynchronization therapy; CRT-P - pacemaker with cardiac resynchronization therapy; VVI/DDD - dual/ /single chamber pacemaker; ICD-VR/DR - dual/single chamber implantable cardioverter-defibrillator.

ously secured vascular approach. In 1 patient, since it was impossible to implant left ventricular lead with acceptable electrical and hemodynamic effect, the left ventricular epicardial lead was implanted through lateral thoracotomy in co-operation with a cardiothoracic surgeon. It was connected with the device in the pocket in the left subclavian area. The total number of new implanted leads was as follows: 32 defibrillating leads, 42 pacing leads including 27 left ventricular leads in the coronary sinus system and one epicardial lead.

The planned clinical target - effective resynchronization therapy - was obtained in all patients.

The duration of the procedures and fluoroscopy was not systematically noted for the whole study group, therefore it was not included into the statistical evaluation.

No case of death and no severe complications of the procedures such as periprocedural death, fatal avulsion of the heart or great vessels, embolism or heart tamponade requiring emergency sternotomy were recorded.

Intraprocedural dissection of the innominate vein or superior vena cava with intramural hematoma occurred in 3 patients with innominate vein occlusion, but it did not require any surgical intervention. However, in 2 of those 3 patients it additionally hindered the new system implantation and it was necessary to implant the new system on the contralateral side.

In 1 patient, in the first $24 \mathrm{~h}$, and in another one - on the $7^{\text {th }}$ day following the implantation, the dislocation of right ventricular defibrillating lead was observed and it required system revision. 


\section{Discussion}

The clinical experience and current guidelines clearly indicate that the extraction of implanted systems with TLE in patients with systemic or local infection is undisputedly beneficial for the patients [7-12]. In the case of non-infectious indications, the benefits and consequently the indications are not unequivocal. Especially given the fact that some of them are not the electrotherapy complications but rather prevention of future complications [13-18]. There are no randomized clinical trials evaluating such a treatment, but there are new clinical data supporting this strategy [19]. The increasingly greater experience of the operators and growing set of tools allow to refer patients for such a therapy more boldly and on a wider scale, also in the case of patients with leads implanted many years earlier $[4,20]$. It is visible even in the growing number of procedures (Fig. 1) and increasing percentage of non-infectious indications in the described registry as well as in larger groups of patients. In case of every patient the risk-benefit ratio is considered, including also the risk of alternative treatment and life expectancy [2, 21-23].

Taking into consideration the results of the published studies and the experience of our center, it seems that leaving no longer required and not working (6 items) or damaged (21 items) leads, in the majority of patients should be considered a palliative procedure. It would only mean the postponement of the lead extraction problem and in prospect the deterioration of function of the newly implanted, especially multi-lead systems. In such systems, one should anticipate a greater risk of lead interaction. It may result in lead insulation damage, which can not only deteriorate the lead function but also increase the infection risk in the future $[13,17,18,24]$.

In the case of patients with venous system occlusion (7 patients), which hinders the pacing mode change, one can consider the implantation of, e.g. the left ventricular lead from the alternative approach with tunnelization of the lead to primary pocket. Such treatment, despite its potential attractiveness, can lead to loss of venous approach in the future and generate the necessity for epicardial stimulation. The above described procedure including lead extraction in order to regain the venous approach is safe and creates the possibility of effective long-term transvenous stimulation even in spite of occurring technical problems [25-29].

A particular case of venous occlusion obstructing the system development is the occlusion of superior vena cava. Sometimes it appears shortly after implantation with sufficient venous drainage via the collateral circulation, mainly through the azygos vein, and often remains asymptomatic. Alternative central venous approach in such patients is basically limited only to femoral approach. Venous access retrieval, sometimes with the loss of the working lead, enables successful implantation. Often the countertraction from femoral approach as well as long, measuring over $20 \mathrm{~cm}$, peel-away introducers have to be used in such procedures $[3,25,26]$.

A substantial parameter evaluating the quality of patient care is the occurrence of applied therapy complications. In spite of the lack of complications that would require cardiovascular surgical intervention in this group, special attention should be paid to the dissection of vessels with intramural hematoma sometimes present in patients with venous occlusion. Such complication appears in the place where the lead sticks to the wall of the blood vessel, especially where the subclavian and jugular vein as well as superior vena cava and the atrium amalgamate. To avoid extraction of the lead before overcoming the occlusion, the applied tension is not strong enough, which results in the vessel wall destruction by the telescopic sheath. This complication remained clinically silent in the study group and was discovered in venography performed after the unsuccessful attempt of inserting the guide wire. It seems that it can be present in more cases but it is not identified unless the intraprocedural venography is performed. Greater lead tension, which allows to avoid the premature lead extraction, but also too much pressure put on the vessel wall, can be obtained by captivating the lead in the intracardiac part with the stylet inside it. Such method led to successful venous approach retrieval in 1 patient from the study group.

\section{Limitations of the study}

In unicenter registry, the decisions concerning the therapy depend to a significant extent on the experience of the Heart Team referring for such procedures and the way they interpret the guidelines, which may affect the group selection.

The small number of patients in the study group may limit the chance of encountering rare but statistically relevant complications such as tamponade, embolization or heart tear.

The lack of comprehensive data concerning the duration of the procedures and fluoroscopy does not allow to present all data showing indirectly the level of complexity of such procedures. 


\section{Conclusions}

Transvenous lead extraction enables obtaining effective resynchronization stimulation even in the case of excessive number of leads, venous system occlusion after previous implantation or lead damage in resynchronization systems even despite considerable technical problems, especially in patients with venous system occlusion.

Conflict of interest: Aleksander Macią, Paweł Syska, Maciej Sterliński, Artur Oręziak — traveling grants from Cook Medical; Andrzej Przybylski proctor to Cook Medical.

\section{References}

1. Brignole M, Auricchio A, Baron-Esquivias G et al. 2013 ESC guidelines on cardiac pacing and cardiac resynchronization therapy: The task force on cardiac pacing and resynchronization therapy of the European Society of Cardiology (ESC). Developed in collaboration with the European Heart Rhythm Association (EHRA). Europace, 2013; 15: 1070-1118.

2. Duray GZ, Israel CW, Pajitnev D, Hohnloser SH. Upgrading to biventricular pacing/defibrillation systems in right ventricular paced congestive heart failure patients: Prospective assessment of procedural parameters and response rate. Europace, 2008; 10: $48-52$.

3. Maciag A, Syska P, Kuśmierski K, Broy B, Sterliński M. One step behind to step ahead: Femoral approach to stabilize and to extract functional pacing lead to regain venous access Postep Kardiol Int, 2013; 3: 310-312.

4. Maciag A, Syska P, Przybylski A et al. The effectiveness of transvenous leads extractions implanted more than 10 years ago. Cardiol J, 2013; 21: 419-424.

5. Oto A, Aytemir K, Canpolat U et al. Evolution in transvenous extraction of pacemaker and implantable cardioverter defibrillator leads using a mechanical dilator sheath. Pacing Clin Electrophysiol, 2012; 35: 834-840.

6. Marijon E, Boveda S, De Guillebon M et al. Contributions of advanced techniques to the success and safety of transvenous leads extraction. Pacing Clin Electrophysiol, 2009; 32 (Suppl. 1): S38-S41.

7. Wilkoff BL, Love CJ, Byrd CL et al. Heart Rhythm Society; American Heart Association. Transvenous lead extraction: Heart Rhythm Society expert consensus on facilities, training, indications, and patient management: This document was endorsed by the American Heart Association (AHA). Heart Rhythm, 2009; 6: 1085-1104.

8. Kennergren C, Bjurman C, Wiklund R, Gäbel J. A single-centre experience of over one thousand lead extractions. Europace, 2009; 11: 612-617.

9. Rusanov A, Spotnitz HM. A 15-year experience with permanent pacemaker and defibrillator lead and patch extractions. Ann Thorac Surg, 2010; 89: 44-50.

10. Bongiorni MG, Blomström-Lundqvist C, Kennergren $\mathrm{C}$ et al. Scientific Initiative Committee, European Heart Rhythm Association. Current practice in transvenous lead extraction: A European Heart Rhythm Association EP Network Survey. Europace, 2012; 14: 783-786.

11. Bongiorni MG, Marinskis G, Lip GY, Svendsen JH, Dobreanu D, Blomström-Lundqvist C; Scientific Initiative Committee, European Heart Rhythm Association. How European centres diagnose, treat, and prevent CIED infections: Results of an European Heart Rhythm Association survey. Europace, 2012; 14: 1666-1669.

12. Baddour LM, Epstein AE, Erickson CC et al. American Heart Association Rheumatic Fever, Endocarditis, and Kawasaki
Disease Committee; Council on Cardiovascular Disease in Young; Council on Cardiovascular Surgery and Anesthesia; Council on Cardiovascular Nursing; Council on Clinical Cardiology; Interdisciplinary Council on Quality of Care; American Heart Association. Update on cardiovascular implantable electronic device infections and their management: A scientific statement from the American Heart Association. Circulation, 2010; 121: 458-477.

13. Bode F, Himmel F, Reppel M, Mortensen K, Schunkert H, Wiegand UK. Should all dysfunctional high-voltage leads be extracted? Results of a single-centre long-term registry. Europace, 2012; 14: 1764-1770.

14. Silvetti M, Drago F. Outcome of young patients with abandoned, nonfunctional endocardial leads. PACE, 2008; 31: 473-479.

15. Jones SO 4th, Eckart RE, Albert CM, Epstein LM. Large, singlecenter, single-operator experience with transvenous lead extraction: Outcomes and changing indications. Heart Rhythm, 2008; 5: 520-525.

16. Arujuna A, Williams S, Whittaker J et al. Trends, indications and outcomes of cardiac implantable device system extraction: A single UK centre experience over the last decade. Int J Clin Pract, 2012; 66: 218-225.

17. Kolodzinska K, Kutarski A, Grabowski M, Jarzyna I, Małecka B, Opolski G. Abrasions of the outer silicone insulation of endocardial leads in their intracardiac part: A new mechanism of leaddependent endocarditis. Europace, 2012; 14: 903-910.

18. Kutarski A, Trojnar M, Tomaszewski A, Oleszczak K, Głowniak A. Diagnosis and treatment of lead-dependent infective endocarditis. Kardiol Pol, 2011; 69: 502-504.

19. Chudzik M, Kutarski A, Mitkowski P et al. Endocardial Lead Extraction in the Polish Registry: Clinical practice versus current Heart Rhythm Society consensus. Arch Med Sci, 2014; 10: 258-265.

20. Gaynor SL, Zierer A, Lawton JS, Gleva MJ, Damiano RJJr, Moon MR. Laser assistance for extraction of chronically implanted endocardial leads: Infectious versus noninfectious indications. Pacing Clin Electrophysiol, 2006; 29: 1352-1358.

21. Poole JE, Gleva MJ, Mela T et al.; REPLACE Registry Investigators. Complication rates associated with pacemaker or implantable cardioverter-defibrillator generator replacements and upgrade procedures: Results from the REPLACE registry. Circulation, 2010; 122: 1553-1561.

22. HauserRG,Katsiyiannis WT, Gornick CC,AlmquistAK,KallinenLM. Deaths and cardiovascular injuries due to device-assisted implantable cardioverter-defibrillator and pacemaker lead extraction. Europace, 2010; 12: 395-401.

23. Kempa M, Budrejko S, Piepiorka M, Rogowski J, Raczak G, Kozłowski D. Safety and effectiveness of transvenous extraction of pacemaker and implantable cardioverter-defibrillator leads in patients under or over 80 years of age. Kardiol Pol, 2013; 71: 130-135.

24. Williams SE, Arujuna A, Whitaker J et al. Percutaneous lead and system extraction in patients with cardiac resynchronization therapy (CRT) devices and coronary sinus leads. Pacing Clin Electrophysiol, 2011; 34: 1209-1216.

25. Gula LJ, Ames A, Woodburn A et al. Central venous occlusion is not an obstacle to device upgrade with the assistance of laser extraction. Pacing Clin Electrophysiol, 2005; 28: 661-666.

26. Maluenda G, Bustos F, Viganego $\mathrm{F}$ et al. Endovascular recanalization of central venous access to allow for pacemaker implantation or upgrade. Cardiovasc Revasc Med, 2012; 13: 215-218.

27. Ahsan SY, Saberwal B, Lambiase PD et al. An 8-year single-centre experience of cardiac resynchronisation therapy: Procedural success, early and late complications, and left ventricular lead performance. Europace, 2013; 15: 711-717.

28. Palmisano P, Accogli M, Zaccaria $M$ et al. Rate, causes, and impact on patient outcome of implantable device complications requiring surgical revision: Large population survey from two centres in Italy. Europace, 2013; 15: 531-540.

29. van Rees JB, de Bie MK, Thijssen J, Borleffs CJ, Schalij MJ, van Erven L. Implantation-related complications of implantable cardioverter-defibrillators and cardiac resynchronization therapy devices: A systematic review of randomized clinical trials. J Am Coll Cardiol, 2011; 58: 995-1000. 